\title{
Formation of submicrocrystalline structural state of AD31 alloy while rolling in the helical rolls and longitudinal wedge mill
}

\author{
S. Mashekov, A. Mashekova*, A. Alshynova, M. Akimbekova, N. Smagulova \\ Institute of Industrial Engineering, Kazakh National Research Technical University after K. I. Satpayev, \\ 22a Satpayev street, Almaty, Republic of Kazakhstan
}

Received 7 June 2016, received in revised form 13 August 2016, accepted 16 August 2016

\begin{abstract}
The article presents the study of the effect of the number of passes on the parameters of AD31 aluminum alloy microstructure, as well as the effects of the single reduction (aluminum wrought alloys) while rolling of the strips in the helical rolls and on the longitudinal wedge mill. A comparative evaluation of the grain size of ultrafine structures after rolling in the helical rolls and on the longitudinal wedge mill at the deformation temperature of $300^{\circ} \mathrm{C}$ is given. The characteristic parameters of the grain and defect structure are presented. It is shown that the uniform ultrafine grain structure with the size of about 730-850 nm was formed in the sheet material made of AD31 aluminum alloy, which led to the increased strength properties of the alloy and preserved good ductility.
\end{abstract}

K e y w ords: AD31 aluminum alloy, rolling, helical rolls, severe plastic deformation, longitudinal wedge mill, grain size

\section{Introduction}

Aluminum alloys are important and widely used materials in many industries $[1,2]$. Due to the large variety of compounds, known up to date, these materials have a very wide complex of physical and mechanical characteristics. However, continuous improvements of alloy producing and processing methods are required to maintain the leading position in advanced materials for the most popular industries of the present time: aircraft, space, automotive, etc. It is known that the recrystallized ultrafine-grained (UFG) structure (grain size is less than 10 microns) in the aluminum alloys provides high characteristics of strength, ductility and crack resistance, and most importantly, isotropy of mechanical properties. Another advantage of UFG structure in the semi-finished products from aluminum alloys is an extraordinary increase of technological plasticity that allows rolling thin sheets. Then, parts with complex configuration can be manufactured by stamping in the state of superplasticity (SP).

In recent years, methods based on the effect of large plastic deformations gained a widespread inter- est. By use of the method, the structure of metals and alloys can be dramatically ground, and also their properties adjusted [3-7]. According to the numerous publications [3-7], the methods of severe plastic deformation (SPD), such as equal channel angular pressing, torsion under high hydrostatic pressure, multiple isothermal forging, and radial shear rolling, etc. are the most common methods of forming ultramicrocrystalline (UMC) state in the aluminum alloys. The above works and other studies of the last decade [8-11] have shown that the materials, nanostructured by the SPD methods, have high physical and mechanical properties, in addition, they exhibit high and useful strength and ductility properties. Another benefit is that the methods do not change the dimensions of the workpiece and develop macro shear deformations throughout the volume of the metal. Macro shear deformations cause changes in the structure of the metal due to the trans-grains slip, which does not depend on the orientation of the crystal grains. An increase of the level and uniformity of the mechanical properties of metal, as well as a decrease of their anisotropy, are the results of these changes. Despite this, using such technology for manufacturing massive workpieces is

\footnotetext{
*Corresponding author: tel./fax: +7 7011111357; e-mail address: mashekovaaigerim@mail.ru
} 
inefficient due to the low deformation rates, need for a large number of pressing cycles, limitations related to the tooling design.

Intensive macroshifts can be provided by the different technological and constructive ways during sheet rolling process [12]: use of workpieces and rolls with wavy or corrugated surfaces, asymmetric rolling, uneven cooling of the workpiece through its thickness and width, use of crossed rolls and the rolls with a projection on the surface. The authors of work [12] note that in all these cases, intensive macroshifts were achieved due to the local deformation effects in the rolled metal.

In practice, rolled foil has become one of the known and widely used methods among the other methods of SPD [12]. However, because of the small cross-section of the foil, it has little use for subsequent forming operations.

In the paper [13], UFG structure of AlMg10 aluminum alloy was obtained by the ARB method, which was comprised of rolling the pack that consisted of 2 sheets with the draft of min $50 \%$, with the subsequent separation of the rolled products into halves, then its reconnection and rerolling, and so on. It should be noted that the main disadvantage of the ARB method is the low productivity.

The japanese firm JFE Steel offered a method of multiple sequential alternating bending of the steel strip after hot rolling (the method of deformation accumulation by bending) [14]. The work shows that the application of reverse bending allows rolling the sheet blank without changing its thickness in comparison with the conventional rolling. Consequently, this method allows deforming the sheet workpiece indefinitely by the cyclic bending. As a result, the hot-rolled strips with UFG structure can be obtained.

According to work [14], this method can be used in the industry to improve the quality of rolled metal products. This is due to the fact that rolling by the cyclic bending results in obtaining hot-rolled strips with the ferrite grains size of 1 micron or less. Thus,
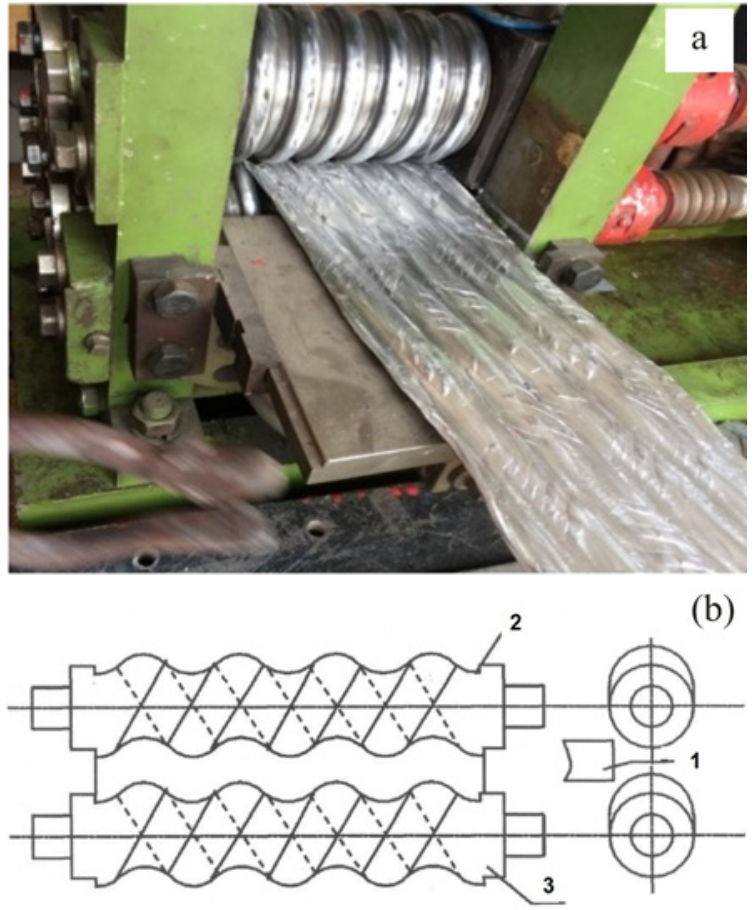

Fig. 1. The rolling mill DUO with the helical rolls: (a) the mill; (b) rolling scheme: 1 - workpiece, 2 - the upper roll, 3 - the bottom roll.

many new designs of rollers are offered in order to improve the quality of sheet products. However, many rollers were not used widely in the production because of the complexity of their manufacture and the difficulty of installing them on rolling mills. Therefore, a tool which has the rolls with the helical working surfaces was developed by the authors of the present article (Fig. 1). The tool was designed to produce the semi-finished products with UFG structure (nanostructure) [15]. Designed tool implements the SPD without changing the original shape and size of the billet. The five-cage mill for the strip rolling has also been developed (Fig. 2) [16].
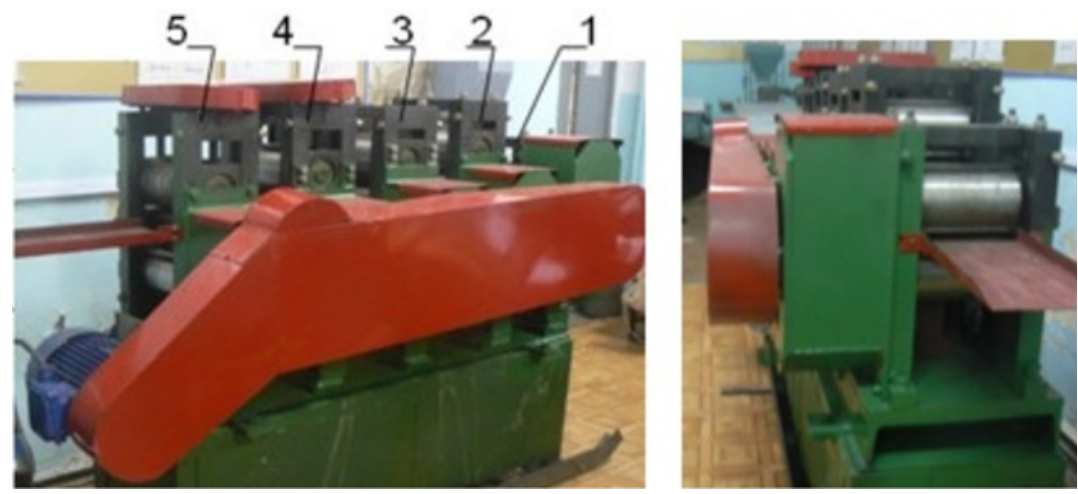

Fig. 2. Five-cage longitudinal wedge mill: 1, 2, 3 - four-rolled cage, without the pressure device; 4,5 - a four-rolled cage with a pressure device. 
The aim of the work is to investigate the evolution of the structure of AD31 aluminum alloy while rolling the strips in the helical rolls and on the longitudinal wedge mill (LWM).

\section{Equipment, materials and methods of the experiment}

Continuous mill of the new design includes a working mill, motor, coupling, bearing powered rolls, working driving rolls, base frame, and base plate. Having an $\mathrm{AC}$ from the motor, the drive cage contains working and supporting rollers of constant diameter, and in the consequent cages the diameter of working rolls is reduced, and the diameter of the backup rolls is increased in the rolling direction. At the same time, the rotation of the rolls is carried out through the individual coupling, reducer, gear cage, and spindle.

It should be noted that the predetermined distance between the working rolls from one cage to the other is increased by the magnitude of advancing.

The tool for providing hot rolling of steel and alloy comprises upper and lower rolls with the helical work surfaces. The projections and depressions of the upper roll are made of the helical lines which are opposite to the depressions and protrusions of the lower roll. Moreover, the angle between the tangent to the spiral lines and the line passing through the point of contact for forming perpendicular to the base roll is from $45^{\circ}$ to $60^{\circ}$. It should be noted that the projections and depressions of the upper and lower rolls have the same width and height or depth, respectively.

While rolling the workpiece in this instrument, protrusions of the working surface on one side of the rollers are disposed oppositely to the depressions of the working surface on the other side of the rolls. The rolling in the first and subsequent passes is carried out by the compression unit $\varepsilon=\Delta h_{\mathrm{B}} H_{0}$ and $\varepsilon=2 \Delta h_{\mathrm{B}} / H_{0}$, where $\Delta h_{\mathrm{B}}$ is the height of the protrusion or depth of depression of the helical working surface, and $H_{0}$ is the workpiece height before rolling. Such rolling ensures the efficient refinement of the structure along the entire volume of the workpiece by alternating bending deformation. The offset of projections and depressions across the width of the rolled strip is formed while rolling, which creates additional macroshifts along the cross section of the workpiece. Such macroshifts lead to extra refinement of metals and alloys structures, i.e. create supplementary conditions for obtaining high-quality steel.

AD31 aluminum alloy was chosen as the workpiece material with the size of $6 \times 150 \times 400 \mathrm{~mm}^{3}$. The rolling on the mill with the helical rolls was performed in the following modes:

- Mode 1 . Heating at $300^{\circ} \mathrm{C}$, soaking for $2 \mathrm{~h}$, rolling by 2 passes in the helical rolls to a thickness of $5.4 \mathrm{~mm}$; then warming at $300^{\circ} \mathrm{C}$, soaking for $30 \mathrm{~min}$, rolling by 2 passes in the helical rolls to a thickness of $5.0 \mathrm{~mm}$; and after that warming up at $300^{\circ} \mathrm{C}$, soaking for $30 \mathrm{~min}$, rolling on the five-cage LWM to a thickness of $1.5 \mathrm{~mm}$.

- Mode 2. Heating at $320^{\circ} \mathrm{C}$, soaking for $2 \mathrm{~h}$, rolling by 4 passes in the helical rolls to a thickness of $5.4 \mathrm{~mm}$; then warming at $320^{\circ} \mathrm{C}$, soaking for $30 \mathrm{~min}$, rolling by 4 passes in the helical rolls to a thickness of $5.0 \mathrm{~mm}$; and after that warming at $320^{\circ} \mathrm{C}$, soaking for $30 \mathrm{~min}$, rolling on the five-cage LWM to a thickness of $1.5 \mathrm{~mm}$.

- Mode 3 . Heating at $300^{\circ} \mathrm{C}$, soaking for $2 \mathrm{~h}$, rolling by 6 passes in the helical rolls to a thickness of $5.4 \mathrm{~mm}$; then warming at $300^{\circ} \mathrm{C}$, soaking for $30 \mathrm{~min}$, rolling by 6 passes in the helical rolls to a thickness of $5.0 \mathrm{~mm}$; and after that warming at $300^{\circ} \mathrm{C}$, soaking for $30 \mathrm{~min}$, rolling on the five-cage LWM to a thickness of $1.5 \mathrm{~mm}$;

- Mode 4 . Heating at $300^{\circ} \mathrm{C}$, soaking for $2 \mathrm{~h}$, rolling by 8 passes in the helical rolls to a thickness of $5.4 \mathrm{~mm}$; then warming at $300^{\circ} \mathrm{C}$, soaking for $30 \mathrm{~min}$, rolling by 8 passes in the helical rolls to a thickness of $5.0 \mathrm{~mm}$; and after that warming at $300^{\circ} \mathrm{C}$, soaking for $30 \mathrm{~min}$, rolling on the five-cage LWM to a thickness of $1.5 \mathrm{~mm}$.

Rolling in the rolls with the helical working surfaces was performed as follows. The workpiece was fed into the gap between the upper and lower rollers and deformed by the projections and depressions of the rolls with the single reduction of $\varepsilon=\Delta h_{\mathrm{B}} / H_{0}$ in the first pass and with the single reduction of $\varepsilon=2 \Delta h_{\mathrm{B}} / H_{0}$ in the subsequent passes.

The metallographic analysis was performed by using the energy disperse spectrometer JNCAENERGY (England), mounted on the electron probe microanalyzer JEOL at an accelerating voltage of $25 \mathrm{kV}$. The magnification ranges from 40 to 40,000 times.

The quantitative analysis of the defect substructure parameters was carried out by standard methods [17]. The microsections for the metallographic study were prepared according to the traditional methods in the grinding and polishing circles. The concentrated nitric acid solution in ethanol was used for etching samples. Grain size ( $D_{3}$, microns) was determined by secants (by measuring $\sim 300$ grains) on the assumption that the grains have a spherical form, based on the average value of the chord $(X)$, determined by the formula $D_{3}=4 / \pi X_{\text {average }}$.

The mechanical tests for identifying the extension of flat samples were carried out on the universal testing machine Instron 5882. Figure 3 shows a sketch of the sample for the testing. According to the results of tested samples at the room temperature the yield strength $\left(R_{\mathrm{e}}\right)$, tensile strength $\left(R_{\mathrm{m}}\right)$, and elongation $(A)$ were evaluated by the procedures described in GOST 1497-84.

Before the extension test, the samples were subjected to the heat treatment (HT), consisting of hardening and subsequent ageing. The heating tempera- 


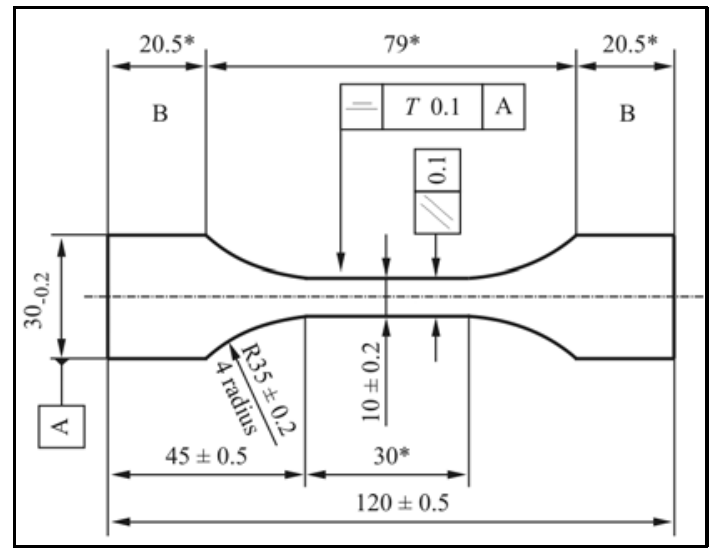

Fig. 3. Sketch of the sample for the extension test.

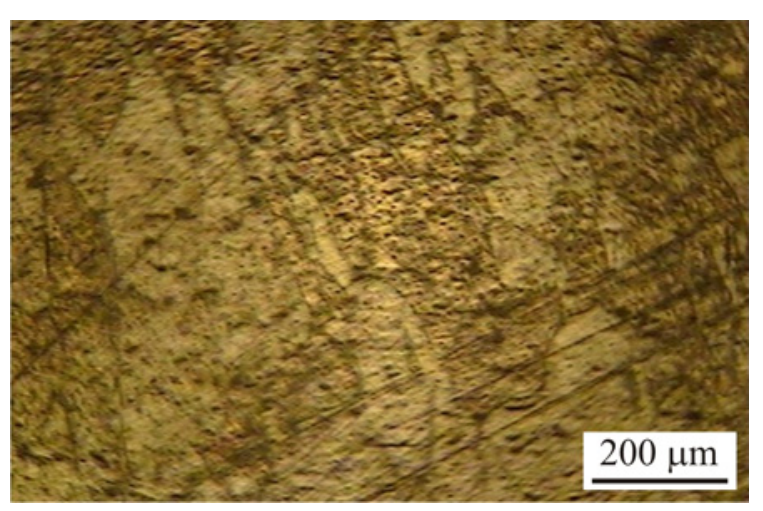

Fig. 4. The initial microstructure of AD31 aluminum alloy.

ture for quenching was $450^{\circ} \mathrm{C}$, soaking at this temperature was $2 \mathrm{~h}$, and cooling in oil was conducted. Ageing was conducted at the temperature of $120^{\circ} \mathrm{C}$ for $5 \mathrm{~h}$.

\section{Results and discussion}

Initially, the workpiece made of AD31 alloy had an inhomogeneous microstructure that consisted of large non-recrystallized grains with an average size of $\sim 362 \mu \mathrm{m}$ in the longitudinal and $\sim 378 \mu \mathrm{m}$ in the transverse directions and spaced along their boundaries in the form of small grains with the size of $\sim 43-$ $47 \mu \mathrm{m}$ (Fig. 4).

The study of the structural state of the AD31 aluminum alloy after rolling in the helical rolls by 2 and 4 passes (modes 1 and 2) showed that microstrip structural state was formed in the cross section, which is perpendicular to the rolling plane (Figs. 5a,b). At the same time, the density of intragranular dislocations increased, the shear strips with the width of $10-45 \mu \mathrm{m}$ were formed. The deformation in the form of shear
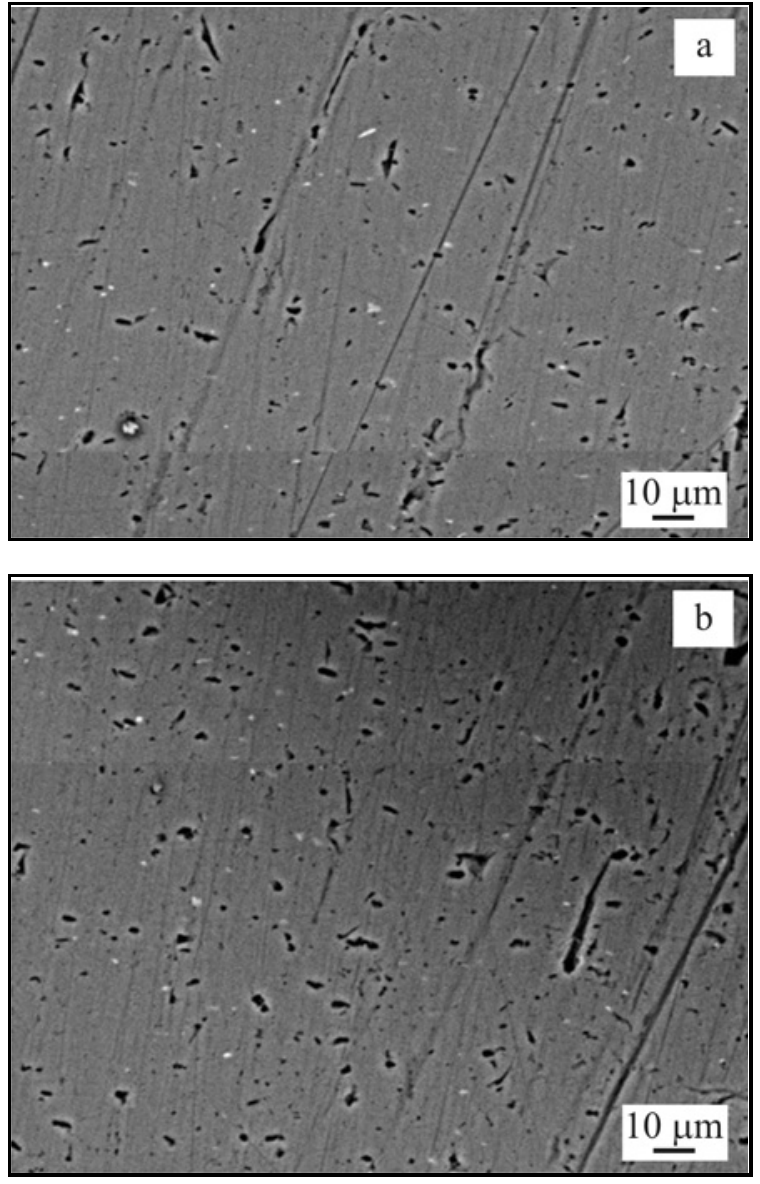

Fig. 5. The microstructure of AD31 alloy after rolling in the helical rolls: (a) after 2 passes; (b) after 4 passes.

strips has occurred mainly within the large grains.

The most likely widths of the microstrips with large-angle boundaries are located in the range of 16$24 \mu \mathrm{m}$ after rolling by 4 passes; the maximum value of this quantity is $\sim 26 \mu \mathrm{m}$ (Fig. $5 \mathrm{~b}$ ). The width of microstrips with low-angle boundaries is varied from 4 to $8 \mu \mathrm{m}$ at the most probable value of about $6 \mu \mathrm{m}$.

Rolling in the helical rolls by 6 and 8 passes (modes 3 and 4; Figs. 6a,b) reduces the width of microstrips and leads to the formation of thinner shear strips on the borders of the initial wide microstrips. A noticeable strip structure with the distance between the borders no more than $15-35 \mu \mathrm{m}$ at the most probable value of $22-8 \mu \mathrm{m}$ occurs after rolling by 6 and 8 passes in the cross-section of the strip (Figs. 6a,b).

Warming of the workpiece at $300^{\circ} \mathrm{C}$ and rolling it in the helical rolls by 2 and 4 passes (modes 1 and 2) led to the formation of additional refinement and grain-subgrain structure of the AD31 aluminum alloy. The size of the individual grains reaches $53-72 \mu \mathrm{m}$ (Figs. 7a,b).

Deformation by 6 and 8 passes in the helical rolls of the workpiece, warmed up at the temperature of 

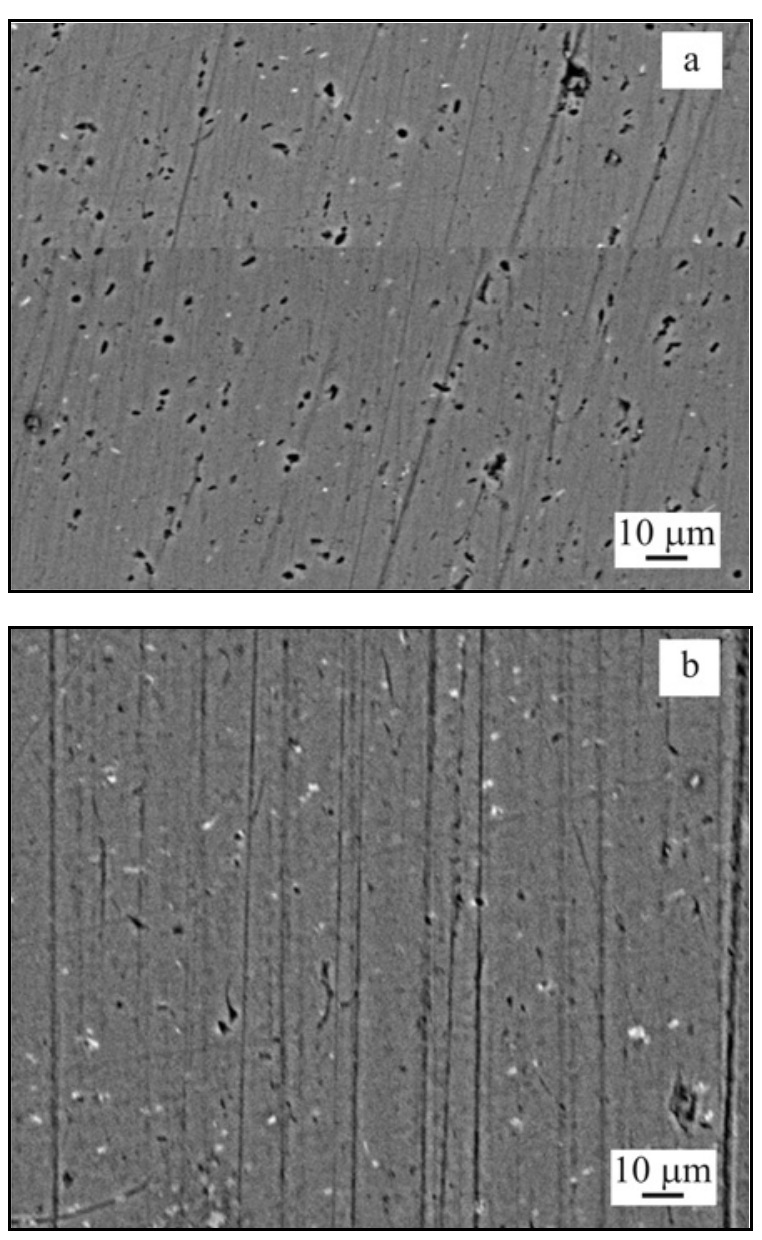

Fig. 6. The microstructure of AD31 alloy after rolling in the helical rolls: (a) after 6 passes; (b) after 8 passes.

$300^{\circ} \mathrm{C}$ (modes 3 and 4 ), led to the formation of the uniform and equal axis structure on the longitudinal and cross-sections of the workpiece (Figs. 8a,b). At the same time, it is clear that there is a further refinement of the grain-subgrain structure. The polygonized or recrystallized structure with an average grain size of about $21-34 \mu \mathrm{m}$ was formed throughout the volume of the rolled strips as a result of the softening processes in the metal of the workpiece. The large-angle boundaries were formed at the border areas of the grains. The dislocation density is very high, so it was not possible to calculate its value according to the image structure. It should be noted that the grain-subgrain structure is stretched in the direction of the bend in the strips, which were rolled by 8 passes in the helical rolls. Thus, strip structure with a distance between the boundaries not exceeding $2-3 \mu \mathrm{m}$ is formed after rolling by 8 passes in the cross-section of the workpiece (Fig. 8b).

It is known [18-20] that the presence of large angular boundaries proves the implementation of the dislocation-disclination mechanism of reorientation of the crystal lattice, which is developed in two stages:
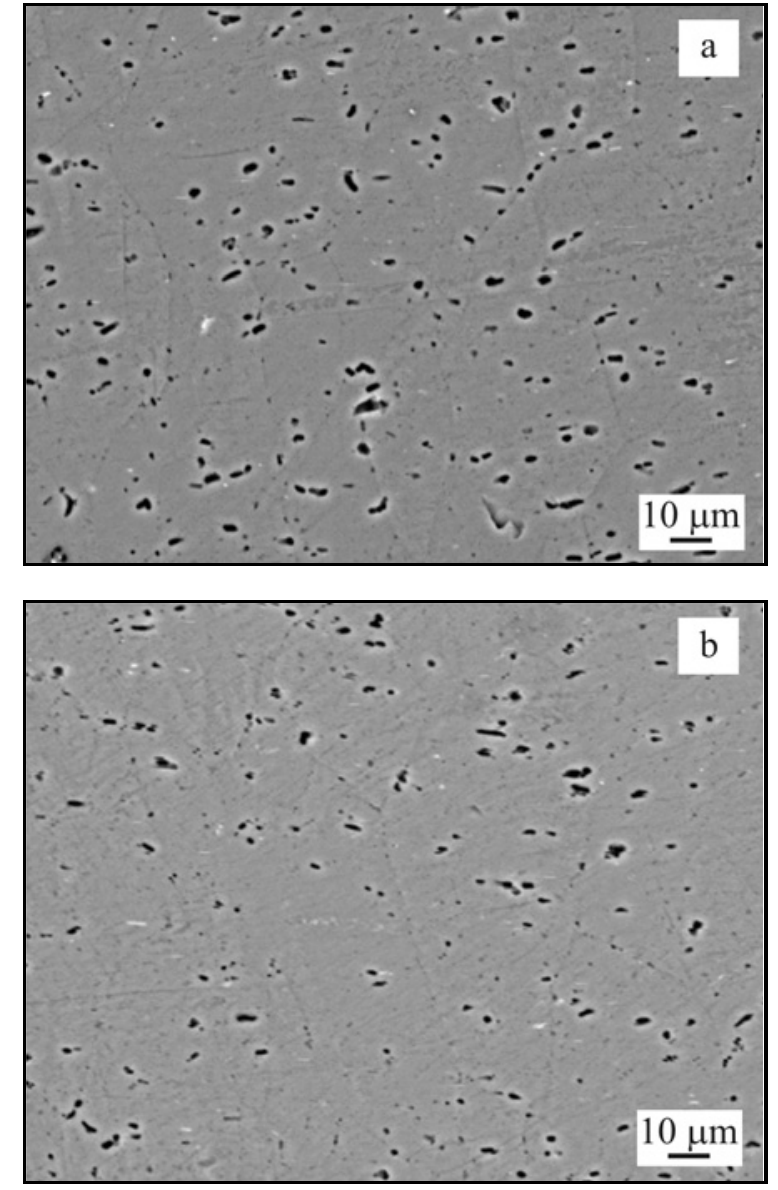

Fig. 7. The microstructure of AD31 alloy after rolling in the helical rolls: (a) after 2 passes; (b) after 4 passes.

the formation of substructure with non-zero components of the tensor density of disclinations, and its collective relaxation in the discrete boundaries of disorientation. This mechanism is one of the universal mechanisms of the crystal fragmentation, including the formation of submicron and nanocrystalline structural conditions in a wide range of metals and alloys.

Thus, while rolling in the helical rolls, the action of the alternating mechanism of deformation provides fragmentation and reorientation of the crystal lattice. The large angular boundaries with high density are formed in the transverse direction of the workpiece.

In order to investigate the effect of rolling on LWM on the formation of an aluminum alloy microstructure, the strips, previously rolled in the helical rolls, were further rolled on the LWM at the temperature of $300^{\circ} \mathrm{C}$ (Figs. 9, 10). The microstructure of the strips made of AD31 aluminum alloy, after rolling in the helical rolls by 2 and 4 passes and then rolling on the LWM (modes 1, 2) is characterized by the presence of subgrains that have been formed inside the former strips of deformation (Figs. 9a,b). The average size of subgrains was $15-21 \mu \mathrm{m}$. 

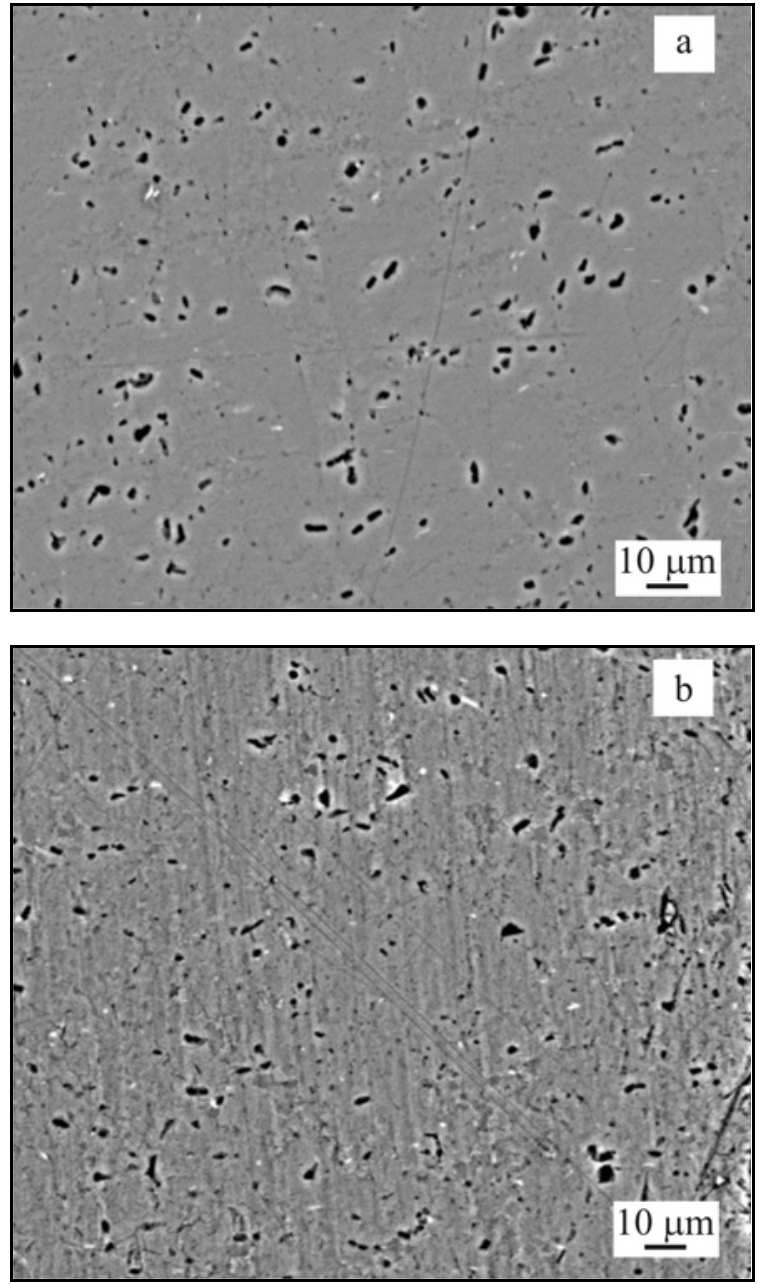

Fig. 8. The microstructure of AD31 alloy after rolling in the helical rolls: (a) after 6 passes; (a) after 8 passes.

Rolling of the workpiece on the LWM (modes 3, 4) leads to the formation of UFG structure with the grain size of $730-850 \mathrm{~nm}$, as a result of softening processes throughout the volume of the rolled strips (Figs. 10a,b). The UFG structure is characterized by the uniformity of the grain size throughout the volume of the material. A clear picture of the grain boundaries was observed on the images of the microstructure after rolling on the LWM. The view of microstructure indicates the formation of grains with predominantly large-angular boundaries.

Thus, the evolution of the structure of AD31 aluminum alloy during rolling in the helical rolls and LWM was maintained as follows:

- formation of the deformation substructure (dislocation and twin) with the width of about $22-28 \mu \mathrm{m}$;

- formation of the cross boundaries in the strips, rise of internal stresses and distortions of the initial crystal lattice;

- development of the softening processes such as polygonization and primary recrystallization resulting
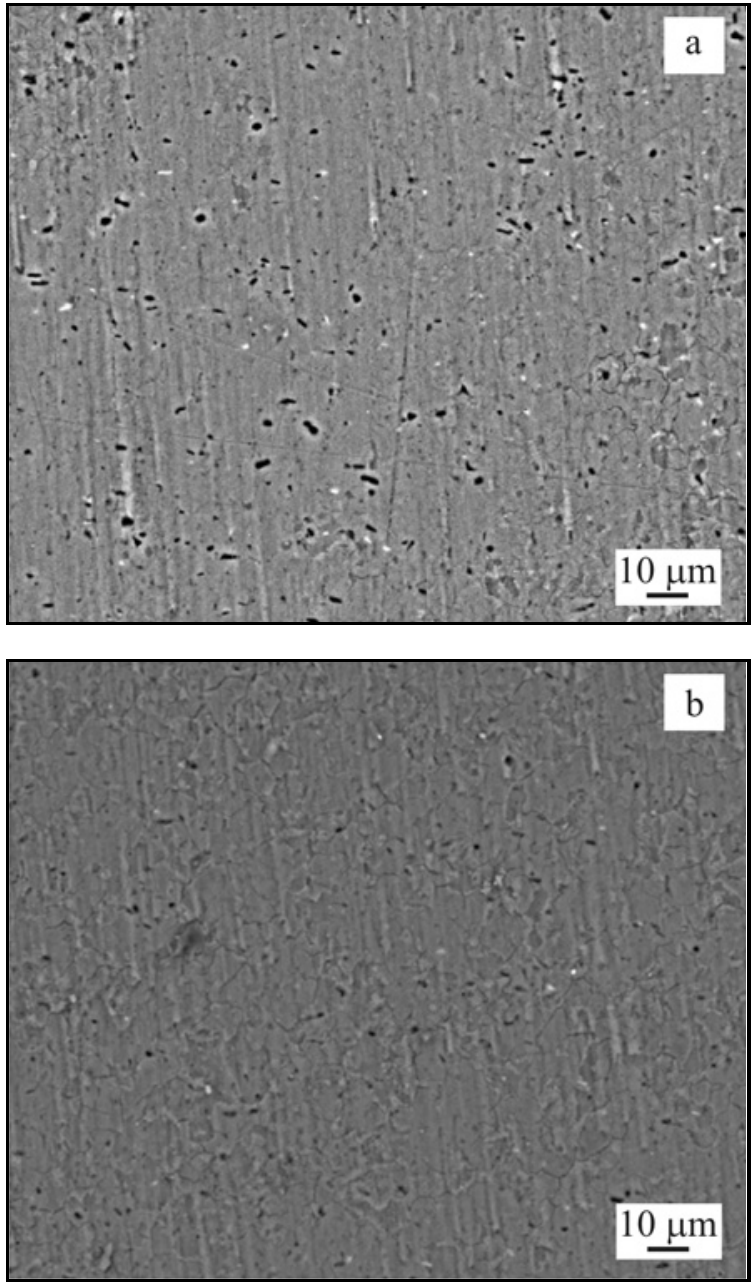

Fig. 9. The microstructure of AD31 alloy after rolling in the helical rolls and LWM: (a) after 2 passes; (b) after 4 passes.

in the formation of UFG structure with the grain size of $730-850 \mathrm{~nm}$.

Results of strength and ductility parameters evaluation of AD31 alloy after rolling in the helical rolls and LWM, as well as HT results, are shown in Table 1. It should be noted that not only the average grain size influences the strength properties of UFG materials, but mainly the nature, size, and distribution of the dispersed particles. Additionally, energy dispersive $\mathrm{X}$-ray microanalysis and mapping of the surface by the elemental composition were conducted, which showed that $\mathrm{Mg}_{2} \mathrm{Si}$ phase was segregated on the boundaries of the AD31 alloy grains.

The alloy, deformed by 2, 4, and 6 passes in the helical rolls and then rolled on the LWM (modes 1, 2,3 ), demonstrates lower levels of strength and ductility, than after rolling by 8 passes in the same rolls and LWM (mode 4). This is due to the structure of the alloy that consists of relatively large and medium grains (depending on the number of passes). Furthermore, it contains stringer clusters of $\mathrm{Mg}_{2} \mathrm{Si}$ phase, an- 
Table 1. Mechanical properties of AD31 alloy (at room temperature) after rolling in the helical rolls and LWM

\begin{tabular}{|c|c|c|c|}
\hline State of AD31 alloy & $R_{\mathrm{e}}(\mathrm{MPa})$ & $R_{\mathrm{m}}(\mathrm{MPa})$ & $A(\%)$ \\
\hline \multicolumn{4}{|l|}{ Along the direction of rolling } \\
\hline Rolling in the helical rolls by 2 passes $+\mathrm{LWM}+\mathrm{HT}$ & 90 & 170 & 22.0 \\
\hline Rolling in the helical rolls by 4 passes $+\mathrm{LWM}+\mathrm{HT}$ & 96 & 178 & 22.1 \\
\hline Rolling in the helical rolls by 6 passes + LWM $+\mathrm{HT}$ & 106 & 197 & 22.3 \\
\hline Rolling in the helical rolls by 8 passes $+\mathrm{LWM}+\mathrm{HT}$ & 118 & 221 & 22.6 \\
\hline \multicolumn{4}{|l|}{ Across the direction of rolling } \\
\hline Rolling in the helical rolls by 2 passes $+\mathrm{LWM}+\mathrm{HT}$ & 91 & 176 & 22.1 \\
\hline Rolling in the helical rolls by 4 passes $+\mathrm{LWM}+\mathrm{HT}$ & 96 & 182 & 23.1 \\
\hline Rolling in the helical rolls by 6 passes $+\mathrm{LWM}+\mathrm{HT}$ & 99 & 202 & 22.8 \\
\hline Rolling in the helical rolls by 8 passes $+\mathrm{LWM}+\mathrm{HT}$ & 108 & 218 & 23.7 \\
\hline
\end{tabular}
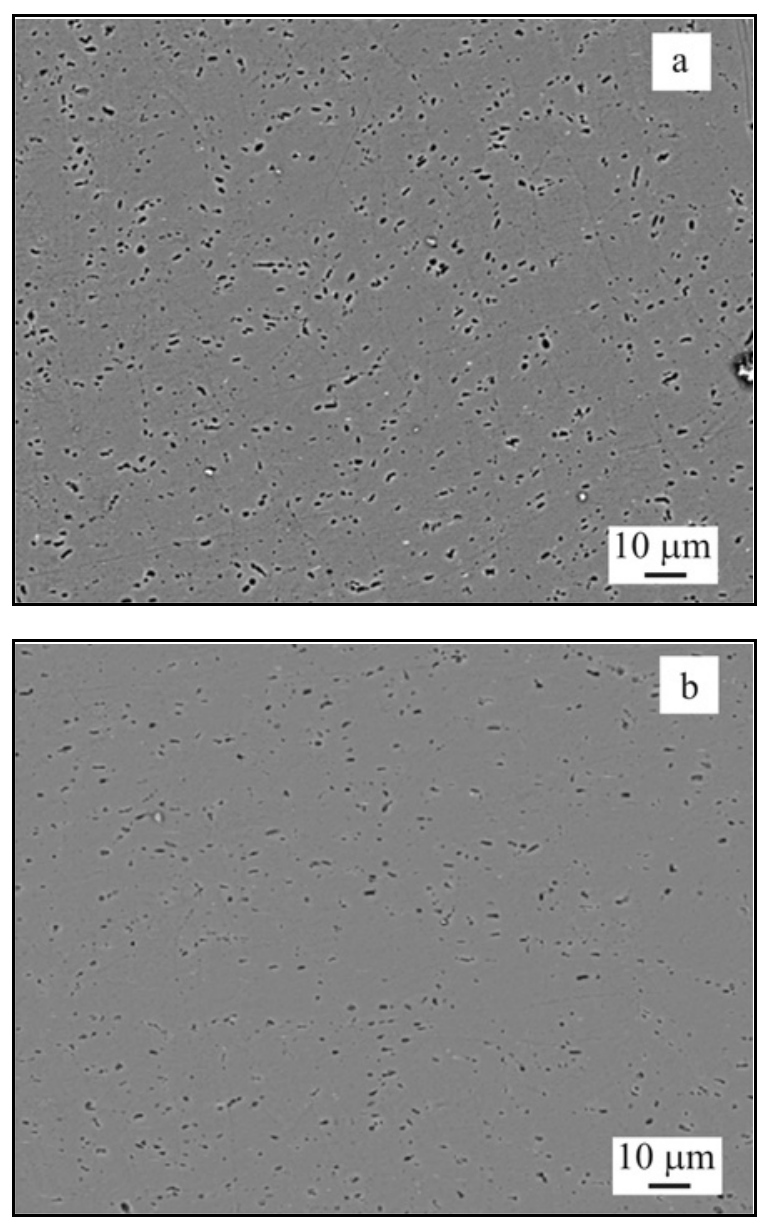

Fig. 10. The microstructure of AD31 alloy after rolling in the helical rolls and LWM: (a) after 6 passes; (a) after 8 passes.

gled by $45^{\circ}$ to the axis of tension. Thus they coincide with the direction of maximum shear stresses action. The decrease of the strength characteristics of the alloy after rolling in the helical rolls by 2, 4, 6 passes is associated with the increase of $\mathrm{Mg}_{2} \mathrm{~S}$ phase volume ratio.
It is shown that AD31 alloy demonstrates the highest mechanical properties after rolling by mode 4. Apparently, this is due to the optimum compromise of structural strengthening, connected with the grain size, and precipitation strengthening, which is in its turn associated with the coherent particles of $\mathrm{Mg}_{2} \mathrm{~S}$ phase in the body of the grain.

\section{Conclusions}

Results of the microstructure evolution study of workpieces at various stages of their production have shown the possibility of obtaining strips with UFG structure by using the intensive plastic deformation. The basic role in the technological scheme of processing belongs to the rolling in the helical rolls which results in the intensive refinement of the structure. Saving enough ductility of aluminum after rolling in the helical rolls allows running shaping operations on the LWM, which contributes to a further refinement of the grain structure of the workpiece, and the formation of a high dislocation density. The uniform formation of a UFG structure with a size of about $730-850 \mathrm{~nm}$ is provided in the sheet material of AD31 aluminum alloy which leads to the increased strength properties of the alloy and preserves good ductility.

\section{References}

[1] Davydov, V. G.: In: Proceedings of the Universities. Non-Ferrous Metallurgy 2001, p. 32.

[2] Kolachev, B. A., Yelagin, V. I., Livanov, V. A.: Metal Science and the Thermal Processing of Non-Ferrous Metals and Alloys. Moscow, MISA 2001.

[3] Valiev, R. Z., Alexandrov, I. V.: Nanostructured Materials, which are Subjected to Severe Plastic Deformation. Moscow, Logos Pub. 2000.

[4] Segal, V. M., Reznikov, V. I., Kopylov, V. I.: Processes of Plastic Structure Forming of Metal. Minsk, Science and Technology 1994. 
[5] Beygelzimer, Y. E., Varyukhin, V. N., Orlov, D. V., Synkov, S. G.: Screw Extrusion - Process of Deformation Accumulation. Donetsk, Firma TEAH 2003.

[6] Maydanyuk, A. P., Stern, M. B., Baglyuk, G. A.: Improving Processes and Equipment for Forming by Pressure in Metallurgy and Mechanical Engineering, 2008, p. 31.

[7] Maydanyuk, A. P., Ryabicheva, L. A., Stern, M. B., Baglyuk, G. A.: Visnik of the East Ukrainian National University named in the memory of Vladimir Dal, 3, 2008, p. 213.

[8] Valiev, R. Z., Alexandrov, I. V.: Bulk Nanostructured Metal Materials. Moscow, ECC Akademkniga 2007.

[9] Krasilnikov, N. A.: Metals, 3, 2005, p. 35. (in Russian)

[10] Efros, B. M., Popova, E. V., Efros, N. B., Ivchenko, V. A., Varyukhin, V. N.: Metals, 6, 2005, p. 31. (in Russian)

[11] Valiev, R. Z.: Nanotechnologies in Russia, 1, 2006, p. 208.

[12] Trayno, A. I., Polukhin, V. P., Nikolaev, V. A.: Metallurgist, 5, 2011, p. 57.

[13] Grechnikov, F. V., Popov, I. P., Erisov, Y. A.: Bulletin of Samara Scientific Center of the Russian Academy of Sciences, 15, 2013, p. 165.
[14] Matsubara, Y., Nakata, N., Hiruta, T.: ISIJ Int., 53, 2013, p. 274. doi:10.2355/isijinternational.53.274

[15] Mashekov, S. A., Absadykov, B. N., Kurmangaliyeva, L. A., Sekerbek, A. M., Biyakaeva, N. T.: The Tool for Hot-Rolling Metals and Alloys (RK Patent 16804). Astana, Ministry of Justice of the Republic of Kazakhstan 2006.

[16] Mashekov, S. A., Mashekova, A. S., Nugman, Y. Z., Smailova, G. A., Seidvalieva, A. R., Biyakaeva, N. T., Ashkeyev, Z. A.: Continuous Mill for Rolling Strips of Steels and Alloys (RK Patent 20969). Astana, Ministry of Justice of the Republic of Kazakhstan 2009.

[17] Utevsky, L. M.: Diffraction Electron Microscopy in Metallurgy. Moscow, Metallurgy 1973.

[18] Ditenberg, I. A., Tyumentsev, A. N., Grinyaev, K. V., Chernov, V. M., Drobyshev, V. A., Potapenko, M. M.: Problems of Atomic Science and Technology, 3, 2012, p. 27. (in Russian)

[19] Ditenberg, I. A., Tyumentsev, A.N., Korznikov, A. V., Chernov, V. M., Potapenko, M. M.: The Physics of Metals and Metallography, 2, 2012, p. 170. doi:10.1134/S0031918X12020020

[20] Tyumentsev, A. N., Ditenberg, I. A.: Russian Physics Journal, 9, 2011, p. 26. (in Russian) 